\title{
Derleme
}

\section{Süt ve Süt Ürünlerinde Aflatoksin M1}

\section{Süt ve Süt Ürünlerinde Aflatoksin M1: Maruziyet ve Sağlık Riskleri}

\author{
Berna Madalı ${ }^{1}$, Aylin Ayaz ${ }^{1}$ \\ ${ }^{1}$ Hacettepe Üniversitesi, Sağglk Bilimleri Fakültesi, Beslenme ve Diyetetik Bölümü, Ankara, Türkiye
}

\begin{abstract}
Özet
Aflatoksinler, Aspergillus flavus (Asp.flavus) ve Aspergillus parasiticus (Asp. parasiticus) küfleri tarafindan temel olarak üretilen yüksek düzeyde toksik sekonder metabolitlerd ir. Özellikle karaciğere toksik etki gösteren bu mikotoksin grubu, başta tahıl ürünleri olmak üzere yanlış depolama sonucu birçok tahıl ürününde ve kontamine tahıl ürünlerini tüketen hayvanların yenilebilir dokularında bulunmaktadır. Yenilebilir hayvan dokuları arasında en fazla aflatoksin kalıntısı içeren süt ve süt ürünleri; yetişkinlerden daha duyarlı olan çocukların beslenmesinde de fazla miktarlarda tüketilmektedir. Bu nedenle süt ve süt ürünlerinde bulunan aflatoksinler, halk sağlığın 1 tehdit eden önemli sorunlardan biridir. Ülkemizde piyasada satı̧a sunulan sütlerin aflatoksin düzeylerine yönelik yapılan çalışmaların sonuçlarına göre; Türk Gıda Kodeksi Bulaşanlar Yönetme liğ i'nde belirtilen yasal limitleri aşmadı̆̆ fakat özellikle çocuklarda uzun süreli alımlarda sağlık için risk oluşturabileceği bildirilmektedir. Ayrıca sokak sütü olarak satılan çiğ sütlerin aflatoksin M1 düzeyin in, piyasada satılan sütlere göre daha yüksek miktarda olduğu çalışmalarda gösterilmiştir. Aflatoksin besinlerde ve yemlerde tamamen yok edilemeyeceğinden, sağlik üzerine potansiyel riskleri minimize etmek ve diyetle aflatoksinlerin alımının en düşük düzeylerde tutulması için üretim-tüketim zincirin in her bir aşamasında iyi tarım uygulamalarının benimsenmesi ve önleyici tedbirlerin alınması gerektiği vurgulanmaktadır.
\end{abstract}

Anahtar kelimler: Aflatoksin, süt ve süt ürünleri, maruziyet, aflatoksin metabolizmasl.

Sorumlu Yazar: Berna Madalı, Hacettepe Üniversitesi, Sağlık Bilimleri Fakültesi Beslenme ve Diyetetik Bölümü, +90 (312) 30510 94/194, bmadali@hacettepe.edu.tr 
Review

Aflatoxin M1 in Dairy Products

\title{
Aflatoxin M1 in Dairy Products: Exposure and Health Risks
}

\author{
Berna Madali ${ }^{1}$, Aylin Ayaz ${ }^{1}$ \\ ${ }^{1}$ Hacettepe University, Faculty of Healh Sciences, Department of Nutrition and Dietetics
}

\begin{abstract}
Aflatoxins are toxic secondary metabolites produced by Aspergillus flavus (Asp.flavus) and Aspergillus parasiticus (Asp. Parasiticus) molds. This mycotoxin group, which is particularly to xic to liver, is found in many cereal crops during growth, harvest, post-harvest and improper storage and in edible tissues of animals consuming contaminating cereal products. Dairy products containing the most aflato xin residues in edible animal tissues are consumed large quantities by consumers particularly children who are more vulnerable than. Thus, the AFM1 found dairy product is one of the important problems threatening public health. Studies on the AFM 1 levels of commercially milk in Turkey is indicated that the AFM1 levels of dairy products do not exceed the acceptable maximum legal limits in the Turkish Food Codex Contaminants Regulation but may pose a risk to health, especially during long term intakes in children. Studies have also shown that AFM1 levels of raw milk contain more AFM1 levels than those sold in the market. Because aflatoxins cannot be completely destroyed from foods and feeds, It is emphasized by the relevant experts that measures should be taken by countries to limit the intake of aflatoxins via diet to minimize potential risks to health and to limit the consumption of aflatoxin containing foods at levels that can not be reduced.
\end{abstract}

Keywords: Aflatoxin, dairy product, exposure, aflatoxin metabolism.

Corresponding Author:Berna Madali, Hacettepe University, Faculty of Health Sciences Department of Nutrition and Dietetics, +90 (312) 305 10 94/194, bmadali@ hacettepe.edu.tr 


\section{Giriş}

Aflatoksinler temel olarak dünyada, farklı iklimlerde bulunan yüzden fazla küf türünden oluşan Aspergillus (Asp.) cinsinde bulunan bazı türler tarafindan üretilen poliketit mikotoksinlerin bir grubudur (Bennett, 2010; Iqbal, Asi ve Ariño, 2013). Aflatoksinlerin oluşumu küflerin gelişimiyle yakından ilişkilidir (Jamali ve diğ., 2012). Tarım ürünlerinde temel olarak Asp. flavus ve Asp. parasiticus küfleri ve nadiren de Asp. nomius gibi diğer küf türleri bulunur. Aflatoksinler bu küfler tarafindan üretilen yüksek düzeyde toksik sekonder metabolitlerdir (Bennett, 2010; Iqbal ve diğ., 2013).

Aflatoksin B1 ve G1 laktasyon dönemindeki hayvanlar tarafindan alındığında az bir k1sm1 (\%1-2) sütle birlikte aflatoksin M1 (AFM1) ve M2 (AFM2) olarak at1lır. Aflatoksinlerin metabolik ürünleri olan M1 ve M2 aflatoksinle kontamine olmuş küflü tahıllarla beslenen laktasyon dönemindeki hayvanların sütünde ilk olarak tespit edilmiştir. Aflatoksin M1 ve aflatoksin M2 genellikle süt ve yenilebilir hayvan dokularıyla ilişkili olmasına rağmen aflatoksijenik küfler de bu ürünleri üretebilir. Aflatoksinlerin düzeyi genellikle $\mathrm{AFB} 1+\mathrm{AFG} 1+\mathrm{AFB} 2+\mathrm{AFG} 2$ 'nin toplam miktar1 olarak belirtilmektedir. $\mathrm{Bu}$ toksinler yapısal olarak birbirine benzer özellik gösterirler. Aflatoksin B2 ve G2 sirasiyla, aflatoksin B1 ve G1'in dihidroksi derivatifleri olarak bilinmektedir. Aflatoksin M1 4-hidroksi aflatoksin B1'in, aflatoksin M2 ise 4-hidroksi B2'nin türevidir. AFM1, AFB1'in toksik metaboliti, AFM2 ise AFB2'nin hidroksillenmiş formudur (Coppock, Christian, ve Jacobsen, 2012; Kalantari ve Kalantari, 2007; Pitt, 2014a). İnsanlarda ve hayvanlarda toksisiteye neden olabilen aflatoksinlerin başlıca türleri Şekil 1'de gösterilmiştir.

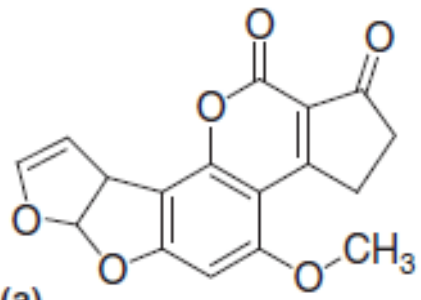

(a)

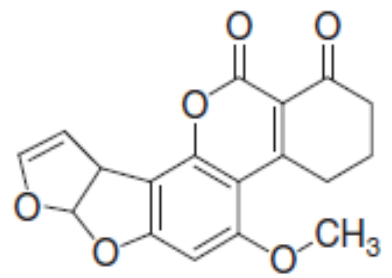

(b)

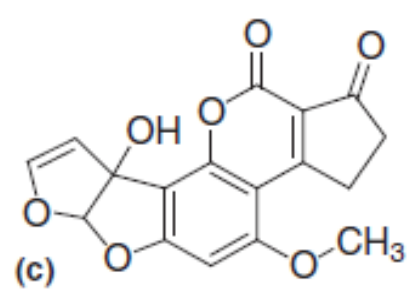

(c)

Şekil 1: Aflatoksin türleri: (a) aflatoksin B1; (b) aflatoksin G1; (c) aflatoksin M1 (Zain, 2011).

Hayvanlar tarafindan tüketilen yemlerdeki aflatoksin B1 ve sütteki aflatoksin M1 miktarı arasında doğrusal bir ilişki olduğu bildirilmiştir (Kamkar, Khaniki, ve Alavi, 2011; Tavakoli, Kamkar, Riazipour, Mozaffari Nejad, ve Rafati, 2013). Çifflik hayvanları üzerinde 
yapılan kontrol çalışmalarında, sütteki aflatoksin B1'in yaklaşı $\%$ 0.3-6.2'sinin aflatoksin M1'e dönüştüğü bulunmuştur (Cavaliere ve diğ., 2006; Creppy, 2002). Fakat bu dönüşüm oranı; hayvanın türüne, süt verme dönemine, sağım zamanına, sağım aralığına ve hayvanın süt verim düzeyine göre değişiklik göstermekle birlikte deneysel olarak aflatoksinin süte taşınma oranı \%1-5 olarak hesaplanmaktadır. İneklerde farklı metabolizmalarından dolayı bu oran \%0.35-3 arasında değişirken, koyunlarda ise \%0.08-0.33 arasındadır (Cavaliere ve diğ., 2006; Rahimi, Nilchian, ve Behzadnia, 2012; Santini ve diğ., 2013).

\section{Aflatoksinlere Maruziyetin Değerlendirilmesi}

Mikotoksin içeren besin ve yemlerin kontaminasyonu tüm dünyayı etkileyen önemli bir sorundur. Gelişmiş ülkelerde çiftlik hayvanlarının küflü tarımsal ürünleri tüketme olasıllğı bulunurken, insanlar tarafından tüketimi pek karşılaşılan bir durum değildir. Dolayısıyla mikotoksin kontaminasyonu gelişmiş ülkelerde insan sağlığından ziyade hayvan sağlığ ını tehdit eden bir sorundur. Gelişmekte olan ülkelerde ise besinlerin yetersiz olması, hatalı besin işleme uygulamaları ve uygun olmayan depolama koşulları insanların yüksek düzeyde mikotoksine maruz kalmalarına neden olmaktadır (Trucksess ve Diaz-Amigo, 2011). Yoksulluk, kuraklık ve diğer yetersizlikler ise insan ve hayvanların mikotoksin maruziyetini arttırır (Khlangwiset, Shephard, ve $\mathrm{Wu}, 2011$ ). Gelişmekte olan ülkelerde nüfusun \%60-85 gibi önemli bir kısmı tarımla uğraşmaktadır. Bu yüzden, besinlerdeki aflatoksin düzeyinin sınırlandırılmasına yönelik düzenleyici yaklaşımlar yetersiz kalmaktadır (Cotty, Probst, ve Jaime-Garcia, 2008). Bunun sonucu olarak gelişmiş ve gelişmekte olan ülkelerde yaşayan insanlar arasında aflatoksin maruziyetinin prevalansında farklılıklar ortaya çıkmaktadır (Egmond ve Jonker, 2003; Williams ve diğ., 2004). Gelişmekte olan ülkelerde halka sunulan hazır besin maddelerinin tüketimi az olup, besin maddelerinin analiz edilmesi için gerekli olan laboratuvarlar ise ekonomik ve teknolojik açıdan yetersizdir. Tüketilen besinler genellikle ailelerin kendilerinin ürettiği, depoladığı ve aflatoksin için risk oluşturabilecek herhangi bir durum dikkate alınmadan hazırlanan yiyeceklerdir. En az kontamine olmuş besin maddeleri ve yemler dışarı satılmakta, daha fazla kontamine olmuş olan ürünler ise aile fertleri tarafindan tüketilmektedir. Bu durum üretici ailenin daha fazla aflatoksine maruz kalmasına neden olmaktadır (Henry, Bosch, Troxell, ve Bolger, 1999).

İnsanlar ve hayvanlar ağız, solunum ve deri yoluyla mikotoksinlere maruz kalabilmekted ir ( Coppock ve Dziwenka, 2014; Tirmenstein ve Mangipudy, 2014). İnsanların 
mikotoksinlere maruziyetinin temel yolu besinlerle birlikte toksinin vücuda alımmasıdır (Raad, Nasreddine, Hilan, Bartosik, ve Parent-Massin, 2014).

Vücuttaki tüm sistemler mikotoksinler için biyolojik hedef olabilmektedir. Biyomarker değerlendirme listeleri (biomarker rubrics) stratejik araçlardır. Biyomarkerlar niteliksel-niceliksel olarak toksikolojik etkilerin, maruziyetin, internal dozun ve hassasiyetin değerlendirilmesine olanak sağlamaktadır (Duarte, Pena, ve Lino, 2011). Aynı zamanda mikotoksin içeren besinlerin tüketimi maruziyetin de göstergesidir. Besinlerin mikotoksin düzeyi vücuttaki mikotoksinlerin miktarını tahmin etmede önemlidir (Coppock ve Dziwenka, 2014).

Mikotoksinlere yönelik yapılan epidemiyolojik çalışmalarda (Pitt, 2014b; Zain, 2011), mikotoksin düzeyini belirlemek ve sürecini değerlendirmek birçok faktöre bağlı olduğu için bu çalışmaları yorumlamak ve çalışma yapmak oldukça zordur. Mikotoksinler; hayvan yemlerinden, et, süt ve yumurta gibi yenilebilen hayvan dokularına belirli düzeylerde geçmektedir. Bunun çalışma sonucunu etkileyecek düzeyde olması maruziyet çalışmalarında değerlendirmeyi zorlaştıran diğer bir etkendir.

Diyetle alınan mikotoksin düzeyi, günlük tüketilen besinlerde bulunan mikotoksin miktarının vücut ağırlığına bölünmesiyle belirlenmektedir. Bu düzey; (mikotoksin( $\mu \mathrm{g}) / \mathrm{besin}$ maddesi(kg)) x tüketilen besin (kg)/vücut ağırlı̆ 1 (kg) ile hesaplanmaktadır (Shephard, Westhuizen, ve Sewram, 2007). Çalışmalarda majör mikotoksin metabolitlerinin atımının ya da serumdaki mikotoksin düzeyinin eksternal dozla ilişkili olduğu gösterilmiştir. $\mathrm{Bu}$ parametreler diyetle alınan düzeyi tahmin etmek için kullanılabilir. İnternal dozun olumsuz biyolojik etkilerle ilişkili olabileceği düşünülmektedir. Bu yüzden mikotoksin maruziyetinden kaynaklanan riski tahmin etmede internal doz kullanımı önerilmektedir (Coppock ve Dziwenka, 2014; Shephard ve diğ., 2007).

Mikotoksinlerde olduğu gibi aflatoksin maruziyetinin değerlendirilmesi de oldukça zordur. Sadece aflatoksinle kontamine olmuş besinlerin toksin düzeyinin belirlenmesi, aflatoksin maruziyetinin değerlendirilmesi için yeterli ve kesin veri sağlamamaktadır. Çünkü aflatoksinler besinlerde homojen olarak dağılmamaktadır. Ayrıca diyetle alınan besinlerin hem çeşidi çok fazladır hem de tüketilen besin miktarları doğru olarak rapor edilememektedir. AFB1 metabolizmasındaki genetik farklılıklar bireysel değerlendirmeleri etkilediği için maruziyetin değerlendirilmesi amaciyla alternatif biyomarkerlar geliştirilmiştir. 
AFB1 maruziyetinin değerlendirilmesinde idrarda aflatoksin-N7-guanin (AFB1-N7-gua) ya da kanda aflatoksin-albümin (AFB1-alb) düzeyleri kullanılabilir (Scussel, 2005).

\section{Besinlerde Aflatoksin Düzeyi}

Aflatoksinler özellikle findık, kuru meyveler, yerfistığı, kakao, kahve, baharatlar, mısır, pirinç, buğday ve diğer tahıl ürünlerinde yüksek düzeylerde bulunmaktadır. Aynı zamanda kontamine olmuş yemle beslenen hayvanlardan elde edilen et, süt, yumurta, peynir ve yoğurt gibi diğer hayvansal ürünlerde de bulunabilirler (Soubra, Sarkis, Hilan, ve Verger, 2009; Yentür ve Er, 2011). Yüksek miktarlarda aflatoksin içeren besinlerin uzun süre tüketimi halk sağlığı açısında problem yaratabileceği gibi ihracatı da olumsuz yönde etkilemektedir. $\mathrm{Bu}$ durum ülkede ekonomik kayılara neden olabilmektedir (Lizárraga-Paulín, MirandaCastro, Moreno-Martínez, Torres-Pacheco, ve Lara-Sagahón, 2013). Bu nedenle besinlerdeki mikotoksin kontaminasyonu, üretimden tüketime kadar geçen her aşamada ülkeler tarafindan kontrol altına alınmalıdır (Banu ve Muthumary, 2010; Yentür ve Er, 2011).

\section{Süt ve süt ürünlerinde aflatoksin M1 düzeyi}

Yetişkin bireylerin beslenmesinde önemli bir yere sahip olan süt ve süt ürünleri, yetişkinlerden daha duyarlı olan çocuklar tarafindan fazla miktarlarda tüketilmektedir (Deveci ve Sezgin, 2005). Süt ve süt ürünleri yenilebilir hayvan dokuları arasında en fazla aflatoksin kalıntısı içeren besin grubudur. Bu yüzden süt ve süt ürünlerinde bulunan aflatoksinler halk sağlı̆̆ını tehdit eden önemli sorunlardan biri olarak kabul edilmektedir (Deveci ve Sezgin, 2005).

Süt ve süt ürünlerindeki aflatoksin kontaminasyonunun iki temel yolu vardır. Birinci yol laktasyon dönemindeki hayvanlar, aflatoksinle kontamine olan yemleri tükettiklerinde aflatoksin B1 ve B2, hayvan vücudunda metabolize edilerek aflatoksin M1 ve M2'ye dönüşmektedir. Metabolize edilen bu toksinler, hayvandan elde edilen süte geçerek kontaminasyon oluşmasına neden olmaktadır. İkinci yol ise süt sağıldıktan sonra taşıma, işleme ve depolama sırasında, aflatoksin sentezleyen küflerin süte bulaşması ve aflatoksin üretmeleri ile oluşabilmektedir (Çelik, Sarimehmetoglu, ve Kuplulu, 2005).

Süt ürünlerinde en yüksek aflatoksin düzeylerine peynirlerde rastlanmaktadır. Küf gelişimi özellikle olgunlaştırma süresi uzun olan peynirlerin kabuk kısımlarında daha fazla olmaktadır (Arikan ve Çevik, 2012). Aflatoksinler düşük sıcaklıklarda sentezlenemediği için 
küflerle kontamine olmuş peynirlerin $+4^{\circ} \mathrm{C}$ 'de depolanmaları aflatoksin sentezini önlemektedir. Piyasada bulunan ticari sütlerde aflatoksin M1 in görülme sıklığı, ham çiftlik sütlerinden daha fazladır. Bunun sebebi, farklı hayvanlardan toplanan aflatoksin M1 ile kontamine olmuş sütler, diğer sütlerle karıştırıldığında tamamının kontamine olmasıdır. Kontamine olmuş yemle beslenen hayvanın sütünde bulunan aflatoksin M1'in süt içerisideki dağılımı homojen değildir. Sütten kremanın ayrılması işlemi, sütün içerisindeki AFM1 dağılımını etkilemektedir. Bu işlem sırasında süt içerisindeki AFM1'in yaklaşık \%10'u yağa geçmekte, \% 80‘inden fazlası ise süt proteini olan kazeine bağlanarak yağsız süt kısmında kalmaktadır (Ayyildiz, 2012; Galvano, Galofaro, ve Galvano, 1996).

Aflatoksin M1, sütlerde yaza kıyasla, kış aylarında daha yüksek düzeylerde bulunmaktadır. Yaz mevsiminde sütte bulunan AFM1'in daha düşük düzeyde olması hayvanların çayır, otlak ve yeşil samanlık ta taze yemlerle beslenmesine bağlanmaktadır. Buna karşın kış mevsiminde, taze yeşil yeme ulaşımın mümkün olmaması ya da yem eksikliğinden dolayı hayvanların beslenmesi daha yoğun olarak mısır, buğday ya da pamuk çekirdekleri gibi tahıl ürünlerine dayalıdır. Uygun olmayan depo koşulları, bu tahıl ürünlerinde yükssek düzeylerde mikotoksin üretilmesine neden olmaktadır. Aynı zamanda, süt verimi kışın daha düşük olduğu için aflatoksin M1 ve diğer bileşenler sütte daha konsantre bulunmaktadır (Kamkar, 2008; Mulunda, Bakunzi, Motsei, Ngoma, ve Nyirenda, 2013; Rahimi, S hakerian, Jafariyan, Ebrahimi, ve Riahi, 2009).

\section{Aflatoksinlerin Metabolizması}

Mikotoksinlerin metabolizması üzerine yapılan çalışmalarda, genellikle aflatoksin metabolizması üzerinde durulmaktadır. Aflatoksinlerin metabolizmasını araştıran çalışmaların çoğu hayvan dokuları kullanılarak yapılan in vivo ve in vitro çalışmalardır. İnsanlar üzerinde yapılan çalışmalar ise oldukça sınırlıdır (Caloni, Stammati, Friggè, ve De Angelis, 2006; Hussein ve Brasel, 2001; Neal, Eaton, Judah, ve Verma, 1998; Troxel, Reddy, O'Neal, Hendricks, ve Bailey, 1997).

Aflatoksinler yağda yüksek oranda çözünen bileşikler olup, başta solunum yolu ve gastrointestinal bölge olmak üzere maruziyetin olduğu alandan hızlıca emilirler (Agag, 2004). Aflatoksinler, ağız yoluyla vücuda alındığında daha fazla emilir. Deri yoluyla bir maruziyet söz konusu olduğunda ise emilim daha yavaştır. Yoğun metabolizmaları sonunda büyük bir kısmı yavaşça atılır. Aflatoksin B1'in alındığı düzeyin \%65'i kandan 90 dk'da 
uzaklaştırılırken, vücuttan ilk olarak safra yoluyla atımı gerçekleşmektedir. Aflatoksinlerin plazmada yarılanma ömrü kısadır. İnsan karaciğerinde ise aflatoksinin temel bileşiklerinin yarılanma ömrünün $13 \mathrm{dk}$ olduğu tahmin edilmektedir (Bbosa ve diğ., 2013; Tirmenstein ve Mangipudy, 2014). Aflatoksin M1, AFB1 yemle alındıktan sonra, 6-24 saat içinde sütte tespit edilebilmekte, 12-48 saat içinde ise maksimum düzeye ulaşmaktadır. Aflatoksin B1 içeren besinlerin alımı kesildikten 72-96 saat sonra hayvanın sütündeki aflatoksin miktarı azalmaya başlamaktadır (Kamkar, Fallah, ve Mozaffari Nejad, 2014; Tsakiris ve diğ., 2013).

Aflatoksin içeren besinler vücuda alındıktan sonra kan dolaşımına geçerler ve hücre membranlarından emilirler. Kandan farklı dokulara, karaciğere ve ksenobiyotik metabolizmasının temel organlarına dağıtılırlar. Aflatoksinler, temel olarak daha az zararlı olan aflatoksin M1 için hidroksilata ya da reaktif epokside karaciğer tarafindan metabolize edilirler (Bbosa ve diğ., 2013).

Metabolize edilmesinde sitokrom P450 enzim sistemi rol oynamaktadır. In vitro ortamda AFB1' in karaciğerdeki metabolizmasını araştıran bir çalışmada, aflatoks in B1 için 5 farklı metabolik yolak olduğu gösterilmiştir (Tirmenstein ve Mangipudy, 2014). Bunlar; indirgeme, hidroksilasyon, hidrasyon, O-demetilasyon ve epoksidasyondur. $\mathrm{Bu}$ metabolik olayların sonunda oluşan ürünlerin hepsi glukuronik asit ve sülfatla konjüge olmalarına olanak sağlayan hidroksil gruplarını içerdiği için detoksifiye olurlar (Tirmenstein ve Mangipudy, 2014). Aflatoksin DNA ile kombine olarak DNA ve RNA sentezini baskılar. Bu durum hücre nükleoli ve protein sentezinde yapısal değişikliklere neden olmaktadır (Mangipudy ve Mehendale, 2005; Tirmenstein ve Mangipudy, 2014).

\section{Aflatoksinlerin Sağlık Üzerine Etkileri}

Aflatoksinle kontamine olmuş besin ve yemler, hayvan ve insan sağliğında ciddi sonuçlara neden olabilmektedir. Gelişmekte olan ülkelerde aflatoksinle kontamine olmuş besinlerin tüketiminden dolayı kronik aflatoksin maruziyeti olan insanların sayısının 5 milyardan fazla olduğu ve 4 milyardan fazla insanda da aflatoksinle ilişkili olan hepatosellüler karsinoma gelişimine neden olduğu tahmin edilmektedir (Bbosa ve diğ., 2013). Örneğin, Bat1 Hindistan'da 1974'te aflatoksinden etkilenen 397 kişiden 108'i aflatoksin zehirlenmesi sonucu hayatını kaybetmiştir. Kenya'da 2004 yılında, günlük beslenmesinde aflatoksinle kontamine olmuş misır tüketen 317 kişiden 125'i ölmüştür. Dünya Sağlk Örgütü’ne (WHO) 
göre, aflatoksinlerin hem akut hem de kronik toksisitesi bulunmaktadır (Consolandi ve diğ., 2012; Lewis ve diğ., 2005; Yu, 2012).

Fakir ve gelişmemiş olan ülkelerde yaşayan insanların orta ve düşük düzeyde aflatoksine uzun süreli maruz kalması sonucu, bireyler kronik aflatoksikozisle karşılaşabilirler. Aflatoksin zehirlenmesinin ilk semptomları kilo kaybı ve anoreksiyadır (Mangipudy ve Mehendale, 2005). Aflatoksin, özellikle gelişmemiş ülkelerde yaşayan çocukların çoğunda marasmus ve kwashiorkorla ilişkilendirilmiştir. Anne sütü aracilığıyla anneden bebeğe aflatoksin geçebilmektedir. Maternal ve kordon kan örnekleri incelendiğinde, insanlarda aflatoksinin transplesantal geçişinin olduğu gösterilmiştir (Denning, Allen, Wilkinson, ve Morgan, 1990). Ağız yoluyla alınan aflatoksinin sütle birlikte \%0.09-0.43 arasında atımının olduğu düşünülmektedir (Mangipudy ve Mehendale, 2005). Aynı zamanda aflatoksin, fetüsün gelişimini de olumsuz yönde etkilemektedir (Bbosa ve diğ., 2013). Bazı toplumlarda karaciğer kanserinin erken başlangıcında rol oynadığı düşünülmesine rağmen prenatal maruziyetinin aflatoksin maruziyetinde önemli bir yerinin olmadığı gösterilmiştir (Mangipudy ve Mehendale, 2005).

Hayvan çalışmalarında, aflatoksinin TNF- $\alpha$ düzeyinde azalmaya neden olduğu belirtilmiştir (Abbès, Salah-Abbès, Abdel-Wahhab, ve Ouslati, 2010; Moon, Rhee, ve Pyo, 1999). Aflatoksin immünosupresan olduğu için HIV ve tüberkülozla da ilişkilendirilmektedir. Yapılan çalışmalarda, aflatoksinlerin Reye sendromuyla ilişkili olduğu belirtilmiştir (Barrett, 2005; Bbosa ve diğ., 2013). Reye sendromu, genellikle influenza (grip) veya suçiçeği gibi bir viral enfeksiyondan sonra özellikle aspirin alınmasıyla ortaya çıkmaktadır. Tam olarak sebebi bilinmese de mitokondri yapılarının metabolik fonksiyonlarındaki bozulmayla ilişkili olduğu düşünülmektedir. Başta karaciğer ve beyin olmak üzere birçok organ etkilenmektedir (Barrett, Hurwitz, Schonberger, ve Rogers, 1986).

\section{Aflatoksinlere Yönelik Yasal Düzenlemeler}

Aflatoksinlerin besinlerdeki düzeyi ve insanlarda maruziyeti kesin olarak belirlenemediği için Gıda Katkı Maddeleri Ortak Uzmanlar Komitesi (JECFA) tolere edilebilir alım düzeyi için herhangi bir limit bildirmemiştir. Bunun yerine potansiyel riskleri minimize etmek için diyetle aflatoksinlerin alımının en düşük düzeylerde tutulması ve azaltılamayacak düzeylerde aflatoksin içeren besinlerin tüketiminin ise sunılandırılması için 
ülkeler tarafindan önlemlerin alınması gerektiğini vurgulanmaktadır (Joint FAO/WHO Expert Committee on Food Additives [JECFA]).

Türk Gıda Kodeksi Bulaşanlar Yönetmeliği’ne (2011) göre çiğ süt, ssıl işlem görmüş süt ve süt bazlı ürünlerin üretiminde kullanılan sütlerde aflatoksin M1'in maksimum limiti $0.050 \mu \mathrm{g} / \mathrm{kg}$ 'dır. Bu düzey bebek formülleri ve devam formüllerinde $0.025 \mu \mathrm{g} / \mathrm{kg}$ 'dır (Ulven ve diğ., 2011).

Besinlerde Bulunan Kontaminantlar (CONTAM) paneli (2007) ve Besin Güvenlik Komitesi'nin (FSC) 2013 raporuna göre, AFM1 ve AFB1 için ALARA'nın (alınabilecek en düşük düzeylerde alım) olması gerektiği bildirilmiştir (Armendáriz, Fernández, Gironés, ve de la Torre, 2014; Food Safety Commission of Japan [FSCJ], 2013). Avrupa Gıda Güvenliği Otoritesi (EFSA), besinlerde ve yemlerde aflatoksinler tamamen yok edilemeyeceği için Tolere Edilebilir Tahmini Haftalık Alım Düzeyi (PTWI) ve Tolere Edilebilir Tahmini Günlük Alım Düzeyi'ni (PTDI) belirtmemiştir. Bunun yerine toksinler için alınabilecek en düşük düzeylerde alımı (ALARA) vurgulamaktadır (European Food Safety Authority [EFSA], 2004).

\section{Sonuç ve Öneriler}

Küflerin ürettiği mikotoksinler, tarladan sofraya kadar her aşamada besini kontamine ederek insan sağlığı üzerinde olumsuz etkilere neden olan önemli bir doğal kirleticidir. Besinlerin yeterli kurutma işlemi yapılmadan, uygun olmayan koşullarda depolanması veya taşınması, nem oranının yüksek olduğu yerlerde bekletilmesi mikotoksin kontaminasyonunun başlıca nedenlerid ir.

Sütlerde bulunan AFM1, AFB1 ile kontamine olmuş yemlerle beslenen laktasyon dönemindeki hayvanların metabolizmaları sonucu ya da taşıma, işleme ve depolama sırasında, aflatoksin sentezleyen küflerin süte bulaşması ve aflatoksin üretmeleri sonucunda oluşmaktadır. Süt ve süt ürünleri, AFM1 kalıntısı açısından riskli bir besin grubudur. Toplumdaki duyarlı gruplardan biri olan küçük çocukların besin örüntüsünde süt ve süt ürünleri fazla miktarlarda tüketildiğinden, aflatoksinler halk sağlı̆̆ını tehdit eden önemli sorunlardan biridir. Bu nedenle AFM1 maruziyetinin doğru bir şekilde değerlendirilmesi ve gerekli önlemlerin alınması gerekmektedir. Aflatoksin M1 maruziyetinin değerlendirilmesi; besin tüketim sıklığının ve besin tüketim kaydının doğru bir şekilde alınamaması ve aflatoksinlerin sütlerde homojen olarak bulunamamasından dolayı oldukça zordur. Ayrıca; 
AFB1 metabolizmasındaki genetik farklılıklar da bireysel değerlendirmeleri etkilemektedir. $\mathrm{Bu}$ nedenle maruziyet değerlendirilmesinde alternatif bazı biyomarkerlar geliştirilmiştir (Duarte ve diğ., 2011).

Başta karaciğere toksik etki gösteren AFM1'in sağlık üzerine birçok olumsuz etkisinin olduğu çalışmalarda bildirilmiştir (Bbosa ve diğ., 2013; Abbès ve dĭ̆., 2010; Mangipudy ve Mehendale, 2005). Besinlerde bulunan AFM1, tamamen yok edilemeyeceği için konuyla ilgili uzmanlar tarafindan AFM1'in alınabilecek en düşük düzeylerde alınması (ALARA) önerilmektedir (European Food Safety Authority [EFSA], 2004). Aynı zamanda sağlıklı beslenme önerilerinden biri olan, besinlerde çeşitliliğin sağlanması da AFM1'in besinlerle alımını sınırlandırabilir. Ayrıca AFM1 kontaminasyonunun azaltılması için; süt üretiminden tüketimine kadar geçen her aşamada iyi tarım uygulamalarının benimsenmesi ve bunun için resmi kontrol ve yaptırım mekanizmalarının sağlıklı ve etkin bir şekilde sürdürülmesi gereklid ir. 


\section{Kaynakça}

Abbès, S., Salah-Abbès, J. B., Abdel-Wahhab, M. A., \& Ouslati, R. (2010). Immunotoxicological and biochemical effects of Aflatoxins in rats prevented by Tunisian Montmorillonite with reference to HSCAS. Immunopharmacology and Immunotoxicology, 32(3),514-522.

Agag, B. (2004). Mycotoxins in foods and feeds: 1-aflatoxins. Ass. Univ. Bull. Environ. Res, 7(1), 173205.

Arikan, L., \& Çevik, D. (2012). Aflatoksinler ve Süt Teknolojis indeki Önemi. Aksaray Üniversitesi Aksaray Meslek Yüksek Okulu Süt Topluluğu, 71 .

Armendáriz, C. R., Fernández, Á. J. G., Gironés, M. C. L. R., \& de la Torre, A. H. (2014). Mycotoxins. In P. Wexler (Ed.), Encyclopedia of Toxicology (3 ed., pp. 424-427). Oxford: Academic Press.

Ayyildiz, T. (2012). Organik Süt ve Süt Ürünlerinde Aflatoksin M1 Varlığının Araştırllması. (Yüksek Lisans Tezi Yüksek Lisans Tezi), Celal Bayar Üniversitesi, Manisa.

Banu, N. \& Muthumary, J. (2010). Taxol as chemical detoxificant of aflatoxin produced by Aspergillus flavus isolated from sunflower seed. Health, 2(07), 789.

Barrett, J. R. (2005). Liver cancer and aflatoxin: New information from the Kenyan outbreak. Environmental Health Perspectives, 113(12), A837.

Barrett, M. J., Hurwitz, E. S., Schonberger, L. B., \& Rogers, M. F. (1986). Changing epidemiology of Reye syndrome in the United States. Pediatrics, 77(4), 598-602.

Bbosa, G. S., Lubega, A., Kyegombe, D. B., Kitya, D., Ogwal-Okeng, J., \& Anokbonggo, W. W. (2013). Review of the biological and health effects of aflatoxins on body organs and body systems. In M. Razzaghi-Abyaneh (Ed.), Aflatoxins - Recent Advances and Future Prospects (pp. 239-266). Croatia: INTECH Open Access Publisher.

Bennett, J. W. (2010). An overview of the genus Aspergillus: Caiser Academic Press, Portland.

Caloni, F., Stammati, A., Friggè, G., \& De Angelis, I. (2006). Aflatoxin M 1 absorption and cytotoxicity on human intestinal in vitro model. Toxicon, 47(4), 409-415.

Cavaliere, C., Foglia, P., Guarino, C., Marzioni, F., Nazzari, M., Samperi, R., \& Laganà, A. (2006). Aflatoxin M1 determination in cheese by liquid chromatography-tandem mass spectrometry. Journal of Chromatography A, 1135(2), 135-141.

Consolandi, C., Cremonesi, P., Severgnini, M., Bordoni, R., Peano, C., Bellis, G. D., \& Castiglioni, B. (2012). Array Platform for Food Safety and Quality. In N. Benkeblia (Ed.), OMICs Technologies: Toolsfor Food Science (pp. 13-57). USA: Taylor \& Francis.

Coppock, R. W., Christian, R. R. G., \& Jacobsen, B. J. (2012). Chapter 88 - Aflatoxins. In R. C. Gupta (Ed.), Veterinary Toxicology (Second Edition) (pp. 1181-1199). Boston: Academic Press.

Coppock, R. W., \& M. Dziwenka, M. (2014). Mycotoxins. In R. C. Gupta (Ed.), Biomarkers in Toxicology (pp. 549-562). Boston: Academic Press.

Cotty, P. J., Probst, C., \& Jaime-Garcia, R. (2008). Etiology and management of aflatoxin contamination. In J. F. Leslie (Ed.), Mycotoxins: Detection Methods, Management, Public Health and Agricultural Trade (pp. 287-300). USA: CABI.

Creppy, E. E. (2002). Update of survey, regulation and toxic effects of mycotoxins in Europe. Toxicology Letters, 127(1), 19-28.

Çelik, T. H., Sarimehmetoglu, B., \& Kuplulu, O. (2005). Aflatoxin M1 contamination in pasteurised milk. Veterinarski Arhiv, 75(1), 57-65.

Denning, D. W., Allen, R., Wilkinson, A. P., \& Morgan, M. R. (1990). Transplacental transfer of aflatoxin in humans. Carcinogenesis, 11(6), 1033-1035.

Deveci, O., \& Sezgin, E. (2005). Aflatoxin M1 levels of skim milk powders produced in Turkey. Journal of Food and Drug Analysis, 13(2), 139-142.

Duarte, S. C., Pena, A., \& Lino, C. M. (2011). Human ochratoxin A biomarkers-from exposure to effect. Critical Reviews in Toxicology, 41(3), 187-212.

Egmond, H. P., \& Jonker, M. A. (2003). Food and Agriculture Organization of the United Nations (FAO), Mycotoxin regulations in 2003 and current developments. Retrieved from http://www.fao.org/docrep/007/y5499e/y5499e07.htm\#bm07

European Food Safety Authority (EFSA), (2004). Retrieved from http://www.fao.org/3/a-y5499e.pdf 
Food Safety Commission of Japan (FSCJ) (Temmuz 2013). Aflatoxin M1 in Milk and AflatoxinBlinFeeds(RaporNo:526). Retrievedfrom http//www.fsc.go.jp/english/evaluationreports/nm_toxins/aflatoxin_m1_b1_fs526.pdf

Galvano, F., Ga lofaro, V., \& Galvano, G. (1996). Occurrence and stability of aflatoxin M1 in milk and milk products: a worldwide review. Journal of Food Protection, 59(10), 1079-1090.

Henry, S. H., Bosch, F. X., Troxell, T. C., \& Bolger, P. M. (1999). Reducing Liver Cancer, Global Control of Aflatoxin. Science, 286(5449), 2453-2454.

Hussein, H. S., \& Brasel, J. M. (2001). Toxicity, metabolism, and impact of mycotoxins on humans and animals. Toxicology, 167(2), 101-134.

Iqbal, S. Z., Asi, M. R., \& Ariño, A. (2013). Aflatoxins. In S. Maloy \& K. Hughes (Eds.), Brenner's Encyclopedia of Genetics (2 ed., pp. 43-47). USA: Institute of Molecular Scieces.

Jamali, M., Ebrahimi, M.-A., Karimipour, M., Shams-Ghahfarokhi, M., Dinparast-Djadid, N., Kalantari, S., Razzaghi-Abyaneh, M. (2012). An ins ight into the distribution, genetic diversity, and mycotoxin production of Aspergillus section Flavi in soils of pistachio orchards. Folia Microbiologica, 57(1), 27-36. doi:10.1007/s12223-011-0090-5

Joint FAO/WHO Expert Committee on Food Additives (JECFA). (t.y.). Risk analys is of mycotoxins by the Joint FAO/WHO Expert Committee on Food Additives (JECFA). Retrieved from http:/www.fao.org/docrep/x2100t/x2100t04.htm

Kalantari, H., \& Kalantari, G. (2007). Evaluation Of Aflatoxins Contamination In Baby Food Supplements (Mamana \& Ghoncheh). Jundushapur Journal of Natural Pharmaceutical Products, 6(1), 42-50.

Kamkar, A. (2008). Detection of aflatoxin M1 in UHT milk sample by ELISA. $J$ Vet Res, 63(2), 7-12.

Kamkar, A., Fallah, A. A., \& Mozaffari Nejad, A. S. (2014). The review of aflatoxin M1 contamination in milk and dairy products produced in Iran. Toxin Reviews, 33(4),160-168.

Kamkar, A., Khaniki, G. R. J., \& Alavi, S. (2011). Occurrence of aflatoxin M1 in raw milk produced in Ardebil of Iran. Iranian Journal of Environmental Health Science \& Engineering, 8(2), 133140.

Khlangwiset, P., Shephard, G. S., \& Wu, F. (2011). Aflatoxins and growth impairment: a review. Critical Reviews in Toxicology, 41(9), 740-755.

Lewis, L., Onsongo, M., Njapau, H., Schurz-Rogers, H., Luber, G., Kieszak, S., Misore, A. (2005). Aflatoxin contamination of commercial maize products during an outbreak of acute aflatoxicosis in eastern and central Kenya. Environmental Health Perspectives, 1763-1767.

Lizárraga-Paulín, E. G., Miranda-Castro, S. P., Moreno-Martínez, E., Torres-Pacheco, I., \& LaraSagahón, A. V. (2013). Novel Methods for Preventing and Controlling Aflatoxins in Food: A Worldwide Daily Challenge. Aflatoxins-Recent Advances And Future Prospects, 93.

Mangipudy, R. S., \& Mehendale, H. M. (2005). Aflatoxin. In P. Wexler (Ed.), Encyclopedia of Toxicology (2 ed., pp. 54-55). USA: Academic Press.

Moon, E., Rhee, D., \& Pyo, S. (1999). Inhibition of various functions in murine peritoneal macrophages by aflatoxin B 1 exposure in vivo. International journal of immunopharmacology, 21(1), 47-58.

Mulunda, M., Bakunzi, F., Motsei, L., Ngoma, L., \& Nyirenda, M. (2013). A Decade of Aflatoxin M1 Surveillance in Milk and Dairy Products in Developing Countries (2001-2011): A Review. In H. A. Makun (Ed.), Mycotoxin and Food Safety in Developing Countries (pp. 39-60). Croatia: INTECH Open Access Publisher.

Neal, G., Eaton, D., Judah, D., \& Verma, A. (1998). Metabolism and Toxicity of Aflatoxins M 1 and B 1 in Human-Derivedin VitroSystems. Toxicology and applied pharmacology, 151(1), 152158.

Pitt, J. I. (2014a). Mycotoxins: Aflatoxins. In Y. Motarjemi (Ed.), Encyclopedia of Food Safety (pp. 289-294). Waltham: Academic Press.

Pitt, J. I. (2014b). Mycotoxins: Mycotoxins - General. In Y. Motarjemi (Ed.), Encyclopedia of Food Safety (pp. 283-288). Waltham: Academic Press.

Raad, F., Nasreddine, L., Hilan, C., Bartosik, M., \& Parent-Massin, D. (2014). Dietary exposure to aflatoxins, ochratoxin A and deoxynivalenol from a total diet study in an adult urban Lebanese population. Food and Chemical Toxicology, 73, 35-43. 
Rahimi, E., Nilchian, Z., \& Behzadnia, A. (2012). Presence of aflatoxin M1 in pasteurized and UHT milk commercialized in Shiraz, Khuzestan and Yazd, Iran. Journal of Chemical Health Risks, l(1).

Rahimi, E., Shakerian, A., Jafariyan, M., Ebrahimi, M., \& Riahi, M. (2009). Occurrence of aflatoxin M1 in raw, pasteurized and UHT milk commercialized in Esfahan and Shahr-e Kord, Iran. Food Security, 1(3), 317-320.

Santini, A., Raiola, A., Ferrantelli, V., Giangrosso, G., Macaluso, A., Bognanno, M., . . . Ritieni, A. (2013). Aflatoxin M1 in raw, UHT milk and dairy products in Sicily (Italy). Food Additives \& Contaminants: Part B, 6(3), 181-186.

Scussel, V. M. (2005). Aflatoxin and Food Safety: Recent South American Perspectives. In H. K. Abbas (Ed.), Aflatoxin and Food Safety (s. 39). USA: CRC Press.

Shephard, G., Van der Westhuizen, L., \& Sewram, V. (2007). Biomarkers of exposure to fumonisin mycotoxins: a review. Food additives and contaminants, 24(10), 1196-1201.

Soubra, L., Sarkis, D., Hilan, C., \& Verger, P. (2009). Occurrence of total aflatoxins, ochratoxin A and deoxynivalenol in foodstuffs available on the Lebanese market and their impact on dietary exposure of children and teenagers in Beirut. Food additives and contaminants, 26(2), 189200.

Tavakoli, H. R., Kamkar, A., Riazipour, M., Mozaffari Nejad, A., \& Rafati, H. (2013). Assessment of aflatoxin M1 levels by Enzyme-linked Immunosorbent Assay in yoghurt consumed in Tehran, Iran. Asian J Chem, 25, 2836-2838.

Tirmenstein, M. A., \& Mangipudy, R. (2014). Aflatoxin. In P. Wexler (Ed.), Encyclopedia of Toxicology (pp. 104-106). Oxford: Academic Press.

Troxel, C. M., Reddy, A. P., O'Neal, P. E., Hendricks, J. D., \& Bailey, G. S. (1997). In V ivoAflatoxin B 1 Metabolism and Hepatic DNA Adduction in Zebrafish (Danio rerio). Toxicology and applied pharmacology, 143(1), 213-220.

Trucksess, M. W., \& Diaz-Amigo, C. (2011). Mycotoxins in Foods. In J. O. Nriagu (Ed.), Encyclopedia of Environmental Health (pp. 888-897). Burlington: Elsevier.

Tsakiris, I. N., Tzatzarakis, M. N., Alegakis, A. K., Vlachou, M. I., Renieri, E. A., \& Tsatsakis, A. M. (2013). Risk assessment scenarios of children's exposure to aflatoxin M1 residues in different milk types from the Greek market. Food and Chemical Toxicology, 56, 261-265.

Ulven, S. M., Kirkhus, B., Lamglait, A., Basu, S., Elind, E., Haider, T., Pedersen, J. I. (2011). Metabolic effects of krill oil are essentially similar to those of fish oil but at lower dose of EPA and DHA, in healthy volunteers. Lipids, 46(1),37-46.

Williams, J. H., Phillips, T. D., Jolly, P. E., Stiles, J. K., Jolly, C. M., \& Aggarwal, D. (2004). Human aflatoxicosis in developing countries: a review of toxicology, exposure, potential health consequences, and interventions. The American Journal of Clinical Nutrition, 80(5), 11061122.

Yentür, G., \& Er, B. (2011). Gidalarda aflatoks in varllğının değerlendirilmesi. Türk Hïyen ve Deneysel Biyoloji Dergisi, 69(1),41-52.

$\mathrm{Yu}$, J. (2012). Current understanding on aflatoxin biosynthesis and future perspective in reducing aflatoxin contamination. Toxins, 4(11), 1024-1057.

Zain, M. E. (2011). Impact of mycotoxins on humans and animals. Journal of Saudi Chemical Society, 15(2), 129-144. 